Elsevier required licence: (c) 2019

This manuscript version is made available under the CC-BY-NC-ND 4.0 license

http://creativecommons.org/licenses/by-nc-nd/4.0/

The definitive publisher version is available online at

https://doi.org/10.1016/j.watres.2019.02.016 


\title{
Simultaneous removal of natural organic matter and micro-organic pollutants from reverse osmosis concentrate using granular activated carbon
}

Shahzad Jamil ${ }^{1}$, Paripurnanda Loganathan ${ }^{1}$, Andrzej Listowski ${ }^{2}$, Jaya Kandasamy ${ }^{1}$, Chinu Khourshed $^{3}$, Saravanamuthu Vigneswaran ${ }^{1 *}$

${ }^{1}$ Faculty of Engineering, University of Technology Sydney (UTS), P.O. Box 123, Broadway, NSW 2127, Australia

${ }^{2}$ Sydney Olympic Park Authority, 8, Australia Avenue, Sydney Olympic Park, NSW, Australia

${ }^{3}$ ICP Laboratory, SSEAU, Mark Wain Wright Analytical Centre, University of New South Wales, NSW 2052, Australia

*Corresponding author. Tel.:+61 2 95142641, fax: +61295142633.

\begin{abstract}
Although reverse osmosis produces high quality reusable water from wastewater the rejected concentrate (ROC) poses potentially serious health hazards to non-target species. This is especially the case when it is disposed into aquatic environments due to the presence of high concentrations of dissolved natural organics, micro-organic pollutants (MOPs) and other pollutants. In batch and column studies we found that granular activated carbon (GAC) was very effective in simultaneously removing dissolved organic carbon (DOC) and 18 MOPs from ROC. The amounts of all DOC fractions adsorbed $(0.01-3 \mathrm{mg} / \mathrm{g})$ were much higher than those of the MOPs $(0.01-2.5 \mu \mathrm{g} / \mathrm{g})$ mainly because ROC contained larger concentrations of
\end{abstract}


DOC fractions than MOPs. However, the partition coefficient which is a measure of the adsorbability was higher for most of the MOPs $(0.21-21.6 \mathrm{~L} / \mathrm{g})$ than for the DOC fractions (0.01-0.45 L/g). The amount of DOC fraction adsorbed was in the order: humics > low molecular weights $>$ building blocks $>$ biopolymers (following mostly their concentrations in ROC). The partition coefficient was in the order: low molecular weights $>$ humics $>$ building blocks > biopolymers. The MOPs were classified into four groups based on their hydrophobicity (log Kow) and charge. The four positively charged MOPs with high hydrophobicity had the highest amounts adsorbed and partition coefficient, with $95-100 \%$ removal in the GAC column. The MOPs that are negatively charged, regardless of their hydrophobicity, had the lowest amounts adsorbed and partition coefficient with 73-94\% removal.

Keywords: adsorption, dissolved organic matter fractions, hydrophobicity, partition coefficient, water treatment

\section{Highlights}

- Simultaneous removal of DOC and micro-organic pollutants (MOPs) from ROC.

- Granular activated carbon (GAC) effectively removes DOC and MOPs from ROC.

- DOC fractions' adsorption on GAC was related to their concentrations in ROC.

- Amounts of MOPs' adsorption were lower than DOC but adsorbabilities much higher.

- MOPs' removal efficacy grouped into 4 classes based on charge and hydrophobicity. 


\section{Introduction}

Global water shortages as a result of widely reported droughts, demands from the world's increasing population and more industrial activity have led to a greater focus on water reuse and recycling. Water recycling by reclaiming wastewater is an attractive option for alleviating this water shortage problem. Reverse osmosis is a widespread and successful process that produces high quality recycled water that can be used as potable and non-potable water. However, a major problem with this process is the generation of reverse osmosis concentrate (ROC) which commonly contains high concentrations of pollutants originally present in the feed wastewater. These pollutants can be nearly 4 times more concentrated in ROC than in wastewater, making it a serious threat to the environment if it is discharged to lands or water bodies without any prior purification process (Jamil et al. 2018). Therefore, proper treatment techniques need to be applied to ROC before it is disposed to land or water.

Of the various pollutants in ROC, natural organic matter (NOM) and micro-organic pollutants (MOP) such as pharmaceutical and personnel care products, endocrine disruptors, pesticides and industrial by-products are common pollutants in ROC produced from wastewater treatment (Nam et al. 2014; Nguyen et al. 2013; Shanmuganathan et al. 2017). NOM at high concentrations in water acts as a substrate for micro-organisms and during its decomposing process use up dissolved oxygen resulting in severe consequences for the aquatic biota. The organics present in ROC mostly resist further biodegradation because they originated from the secondary effluent that has been subjected to extensive secondary treatment. Consequently, they persist in the environment for a long time. Many MOPs have been reported to be toxic to freshwater invertebrates (such as daphniids), fish, mussels, and human embryonic cells at trace concentrations (Pal et al. 2010). Fick et al. (2010) reported that the predicted water concentrations of pharmaceutical products would elevate the plasma 
concentration in exposed fish to a level equal to the human therapeutic plasma concentration. Many of these concentrations are in the nanogram to microgram per litre range (ng/L $-\mu \mathrm{g} / \mathrm{L})$.

Several methods have been used to remove organics from ROC, for example coagulation-flocculation, ozonation, Fenton process, photocatalysis and photo-oxidation, electro-chemical oxidation and adsorption. Of these, the adsorption process is deemed to be the most attractive method due to its simplicity, cost-effectiveness, efficiency at low concentration, and minimal waste production. Granular activated carbon (GAC) is a widely used and versatile adsorbent in water reclamation plants because it can remove many contaminants such as turbidity, nutrients, heavy metals and organics. As such it has routinely been used as a tertiary treatment process in the water industry (Nguyen et al. 2013). Many studies have found that GAC is an efficient adsorbent for the removal of NOM (Cheng et al. 2005; Nguyen et al. 2013; Shanmuganathan et al. 2015; Sounthararajah et al. 2016) and MOP (de Ridder et al. 2009; Jamil et al. 2016; Shanmuganathan et al. 2017; Snyder et al. 2007; Yang et al. 2011,). The high effectiveness of this adsorbent is due to: firstly, its hydrophobic nature; secondly, having organic functional groups to facilitate adsorption of organic constituents; and thirdly, its high surface area and porosity (Eeshwarasinghe et al. 2018). The adsorption of NOM and MOP has been shown to mainly depend on the hydrophobicity of these compounds, for instance log Kow (log (n-octanol/water partition coefficient)) for MOP (Eeshwarasinghe et al. 2018; Nam et al. 2014; Snyder et al. 2007; Wang and Wang 2016). Other properties such as charge, hydrogen bonding, $\pi$-bonding and molecular size have also been used to explain the adsorption behaviour of organics (Cheng et al. 2005; Eeshwarasinghe et al. 2018; Velten et al. 2011).

NOM is composed of several heterogeneous hydrophobic and hydrophilic compounds with widely different molecular sizes. Therefore, it has different abilities to adsorb onto GAC which has a wide pore size distribution and hydrophobicity character. However, only 
limited information is available on the relative effectiveness of removing these compounds (Velten et al. 2011). Most studies on the removal of NOM by GAC considered the composite NOM and not its individual components (Nguyen et al. 2013; Shanmuganathan et al. 2015; 2017; Sounthararajah et al. 2016,). Also, previous studies have investigated the removal of MOP or NOM separately but not many from ROC containing both of these pollutants together, especially the removal of the different constituents of NOM in column-mode experiments. Column-mode experiments are dynamic and more relevant to practical water reclamation plants than the commonly used static batch-mode experiments.

The objectives of this study were to compare: 1 . the removal efficiencies of total DOC and total MOP in ROC by GAC in a batch equilibrium adsorption experiment, 2. the removal behaviour of individual components of DOC in ROC such as biopolymers, humic substances, building blocks and low molecular weight organics by adsorption onto GAC in a column experiment, and 3. the removal behaviour of each of the 18 MOPs in ROC by adsorption onto GAC in a column experiment.

\section{Materials and methods}

\subsection{Reverse osmosis concentrate}

Reverse osmosis concentrate (ROC) collected from an advanced water reclamation plant in Sydney, Australia was used in this study. The plant treats a combination of stormwater and biologically treated sewage effluent. The RO treatment resulted in approximately $72 \%$ of water being recovered, which generated a rejected concentrate (ROC) of about $28 \%$. Range of values reported for ROC characteristics in the treatment plant and values of the samples used in the experiments are summarised in Table 1. 
Table 1. Range of values reported for ROC characteristics in the treatment plant and values of the samples used in the experiments

\begin{tabular}{llll}
\hline Parameter & Unit & $\begin{array}{l}\text { Treatment } \\
\text { plant values }\end{array}$ & $\begin{array}{l}\text { Experimental } \\
\text { value } \\
\text { (Batch/Column) }\end{array}$ \\
\hline $\mathrm{pH}$ & & $7.5-8.2$ & $7.3,8.1$ \\
Conductivity & $\mathrm{mS} / \mathrm{cm}$ & $2.5-3.5$ & $2.5,2.8$ \\
$\mathrm{DOC}$ & $\mathrm{mg} / \mathrm{L}$ & $16-40$ & 22,33 \\
$\mathrm{Mg}$ & $\mathrm{mg} / \mathrm{L}$ & $50-70$ & 53,48 \\
$\mathrm{Ca}$ & $\mathrm{mg} / \mathrm{L}$ & $65-100$ & 70,96 \\
$\mathrm{~K}$ & $\mathrm{mg} / \mathrm{L}$ & $40-80$ & 48,75 \\
$\mathrm{Na}$ & $\mathrm{mg} / \mathrm{L}$ & $350-400$ & 369,383 \\
\hline
\end{tabular}

\subsection{Granular activated carbon}

A coal-based premium grade (MDW4050CB) GAC with a particle size range of 0.42-1.68 mm supplied by James Cumming and Sons Pty. Ltd. was used as the adsorbent. It had an iodine number of $1000 \mathrm{mg} / \mathrm{g}$ and BET surface area of $1000 \mathrm{~m}^{2} / \mathrm{g}$. The average pore size was $30 \AA$ with micropore and mesopore volumes of $25-27$ and $73-75 \%$, respectively (Eeshwarasinghe et al. 2018).

\subsection{Chemical analytical methods}

\subsubsection{Dissolved organics}

The DOC fractionation was performed using a liquid chromatography-organic carbon and nitrogen detector (LC-OCD) system model 8, based on the Grantzel thin film reactor developed by DOC Labor, Dr. Huber, Germany. The LC-OCD is an automated sizeexclusion chromatography system coupled to three detectors, for organic carbon, organic nitrogen and UV absorbance analysis. The measurement procedure has been described in full by Huber et al. (2011). LC-OCD separates the sample into five fractions of organic carbon 
with different molecular weight ranges and chemical polarity. Two major fractions are observed: the hydrophilic chromatographable organic carbon (CDOC) that elutes from the column, and non-chromatographable organic carbon, which is the hydrophobic organic carbon (HOC) fraction that binds irreversibly to the hydrophobic solid phase of the column. CDOC is further fractionated into four major fractions: biopolymers $(>20,000 \mathrm{~g} / \mathrm{mol})$, humic substances (1200-500 g/mol), building blocks (weathering product of humic substances) (500-350 g/mol), and low molecular weight (LMW) organics ( $<350 \mathrm{~g} / \mathrm{mol})$ (Amy et al. 2011; Hubar et al. 2011; Jamil et al. 2016; Shanmuganathan et al. 2015; Velten et al. 2011). The difference between DOC and CDOC is assumed to be the hydrophobic fraction (Huber et al. 2011).

The LC-OCD uses a Toyopearl TSK HW50S column with a phosphate buffer mobile phase of $\mathrm{pH} 6.8$ at a flow rate of $1.1 \mathrm{~mL} / \mathrm{min}$ and the injection volumes were $1 \mathrm{~mL}$. The chromatographic column is a weak cation exchange column containing a polymethacrylate solid phase. Calibration of retention times of the DOC fractions was performed using two standards (Suwannee river Standard II humic acid and fulvic acid from the International Humic Substances Society). The ChromCALC software package (DOC-Labour, Germany) specifically designed for the LC-OCD measurement, was used for data acquisition and data processing, and the amount of each fraction of organic carbon was determined from the chromatogram using a constrained peak-fitting process based on known retention times.

\subsubsection{Micro-organic pollutants (MOP)}

The concentrations of MOPs were determined using solid phase extraction (SPE) followed by liquid chromatograph with tandem mass spectroscopy. $5 \mathrm{~mL}$ analytes were extracted using 500 mg hydrophilic/lipophilic balance (HLB) cartridges (Waters, Milford, MA, USA). These 
analytes were separated using an Agilent (Palo Alto, CA, USA) 1200 series high performance liquid chromatography (HPLC) system equipped with a 150 x $4.6 \mathrm{~mm}, 5 \mu \mathrm{m}$ particle size, Luna C18 column (Phenomenex, Torrance, CA, USA). Mass spectrometry was carried out using an API 4000 triple quadrupole mass spectrometer (Applied Biosystems, Foster City, CA, USA) equipped with a turbo-V ion source employed in both positive and negative electro-spray modes. The correlation coefficients of all calibration curves were $\geq 0.99$.

\subsection{Batch adsorption experiment}

An equilibrium batch adsorption experiment was conducted using a series of glass flasks containing $200 \mathrm{~mL}$ ROC and GAC doses of $0.1,0.5$, and $3 \mathrm{~g} / \mathrm{L}$ by agitating the suspensions in a Ratek Platform Mixer at $120 \mathrm{rpm}$ for $22 \mathrm{~h}$. The suspensions were then filtered through a 0.45 um filter and the filtrates were analysed for DOC and MOP. Percentage adsorption of DOC and MOP was calculated using the equation written as follows:

$$
\text { Percentage adsorption }(\%)=\frac{\left(\mathrm{C}_{0}-\mathrm{C}_{\mathrm{e}}\right)}{\mathrm{C}_{0}} \times 100
$$

where, $\mathrm{C}_{0}$ is initial concentration of DOC $(\mathrm{mg} / \mathrm{L})$ or MOP $(\mu \mathrm{g} / \mathrm{L})$ in ROC, and $\mathrm{C}_{\mathrm{e}}$ is equilibrium concentration of DOC $(\mathrm{mg} / \mathrm{L})$ or MOP $(\mu \mathrm{g} / \mathrm{L})$ in ROC.

\subsection{Column adsorption experiment}

The column experiment was conducted using an acrylic glass tube containing GAC packed to a bed height of $8 \mathrm{~cm}$. A short bed height was deliberately used to obtain a possible quick breakthrough. A stainless-steel sieve was attached to the bottom of the tube to keep the GAC in place and a layer of glass beads was placed on top of the GAC bed in order to provide a 
uniform flow of solution through a fixed-bed column. ROC was passed through the column in the up-flow mode with a velocity of $40 \mathrm{~mL} / \mathrm{min}(6.3 \mathrm{~m} / \mathrm{h})$. A peristaltic pump was used for pumping the ROC through the column. The effluent samples were collected at 10, 30, 60, 90, 120 and $150 \mathrm{~min}$. The samples were then filtered through a $0.45 \mu \mathrm{m}$ filter and the filtrate analysed for the total DOC and its various components. The effluent samples collected at 30, 60 and 90 min were analysed for the individual MOPs.

\subsection{Amounts adsorbed and partition coefficient}

Amounts of the DOC components and MOPs adsorbed were calculated from the column experimental data using the following equation:

$\mathrm{q}=\mathrm{Q} \times \Delta \mathrm{t} / \mathrm{m}\left[\left(\mathrm{Co}-0.5\left(\mathrm{C}_{\text {out }, \mathrm{t}}+\mathrm{C}_{\text {out }, \mathrm{t}-1)}\right)\right]\right.$

where, $\mathrm{q}$ is amounts adsorbed between two consequent times (mg/g GAC), $\mathrm{Q}$ is flow rate (L/min), $\Delta \mathrm{t}$ is time interval between the two sampling times (min), $\mathrm{m}$ is mass of GAC in column (g), Co is influent concentration (DOC, mg/L; MOP, $\mu \mathrm{g} / \mathrm{L}$ ), $\mathrm{C}_{\text {out, }}$ is effluent concentration at time $\mathrm{t}$ (current sampling time (DOC, mg/L; MOP, $\mu \mathrm{g} / \mathrm{L}$ ), and $\mathrm{C}_{\text {out, } t-1}$ is effluent concentration at time t-1 (previous sampling time) (DOC, mg/L; MOP, $\mu \mathrm{g} / \mathrm{L}$ ).

The partition coefficient, $\mathrm{kp}$ was calculated by dividing $\mathrm{q}$ by $\mathrm{C}_{\mathrm{out}, \mathrm{t}}$ for each time period. $\mathrm{kp}$ is the ratio of the amount adsorbed to the equilibrium concentration in solution, which is a measure of the adsorbability of the DOC component or individual MOP on GAC.

\section{Results and discussion}




\subsection{DOC and MOP characteristics}

The concentrations of DOC and MOPs in the ROC are presented in Tables 1 and 2, respectively. Two separate ROC samples were used for the DOC experiments; one with a DOC concentration of $22 \mathrm{mg} / \mathrm{L}$ was used in the batch experiment and the second one with a DOC concentration of $33 \mathrm{mg} / \mathrm{L}$ was used in the column experiment. For the MOP experiments only one ROC sample was used (Table 2). The DOC concentrations of 22 and 33 $\mathrm{mg} / \mathrm{L}$ are within the range of DOC values of $16-40 \mathrm{mg} / \mathrm{L}$ reported for ROC samples from the same treatment plant. These values are 3-10 times higher than the value for the biologically treated sewage effluent (3.6-7.7 $\mathrm{mg} / \mathrm{L}$, Shanmuganathan et al. 2014) that was utilised as the feed water in the RO plant. This indicates that the RO process has rejected all the DOC in the biologically treated sewage effluent during the production of clean water and concentrated them in the ROC.

The LC-OCD analysis revealed that the DOC comprised $2.29 \mathrm{mg} / \mathrm{L}(7 \%)$ of hydrophobic fraction and $31.04 \mathrm{mg} / \mathrm{L}(93 \%)$ of hydrophilic fraction. The hydrophilic fraction contained the following: $24.3 \mathrm{mg} / \mathrm{L}(77 \%)$ of humics; $5.0 \mathrm{mg} / \mathrm{L}(16 \%)$ of low molecular weight neutrals; $1.21 \mathrm{mg} / \mathrm{L}(4 \%)$ of building blocks; and $0.56 \mathrm{mg} / \mathrm{L}(2 \%)$ of biopolymers. The very low concentration of biopolymers may be due to the fact that these high molecular weight biopolymers could have been removed during the microfiltration stage prior to the RO process. Shanmuganathan et al. (2015) also obtained the same order of concentration for the DOC fractions in ROC, except building blocks had slightly higher concentrations than low molecular weight neutrals. In comparison to the results obtained on ROCs, Velten et al. (2011) reported very low values for the different DOC fractions in lake water (DOC, humics, building blocks, low molecular weight organics, and biopolymers concentrations of $1,0.5$, 0.2, 0.05, and $0.05 \mathrm{mg} / \mathrm{L}$, respectively). 
Eighteen MOPs were detected in the ROC and their concentrations ranged from 82 to 19220 ng/L (Table 2). Most of these MOPs were also previously detected in ROC from the same water treatment plant (Shanmuganathan et al. 2017). These MOPs have neutral, positive or negative charges and their degree of hydrophobicity is widely different (log Kow of -0.07 to 4.9). 
Table 2. Properties of the detected MOPs and their initial concentrations in ROC

\begin{tabular}{|c|c|c|c|c|c|c|}
\hline Micropollutants & Compound Class & $\begin{array}{l}\mathbf{M W}^{\mathrm{a}} \\
\text { (g) }\end{array}$ & $\begin{array}{c}\text { Charge }^{b} \\
\text { (pH 7.5) }\end{array}$ & $\begin{array}{l}\text { Conc } \\
\text { (ng/L) }\end{array}$ & $\begin{array}{l}{\log K o w^{a}} \\
(\text { pH 7) }\end{array}$ & pKa \\
\hline Atenolol & Beta-blocker & 266 & + & 128 & $0.16^{\mathrm{f}}$ & $9.6^{\mathrm{f}}$ \\
\hline Benzophenone & Photo initiator & 182 & 0 & 806 & $3.18^{\mathrm{j}}$ & \\
\hline Benzotriazole & Drug precursor & 119 & 0 & 19220 & $1.44^{\mathrm{i}}$ & $0.42^{\mathrm{i}}, 8.37^{\mathrm{i}}$ \\
\hline Bisphenol A & Plastic water bottles & 228 & 0 & 1098 & $3.32^{\mathrm{i}}$ & $9.7^{\mathrm{i}}$ \\
\hline Caffeine & Stimulant & 194 & 0 & 1398 & $-0.07^{\mathrm{e}}$ & $10.4^{\mathrm{e}}$ \\
\hline Carbamazepine & Antiepileptic & 236 & 0 & 1286 & $2.45^{\mathrm{i}}$ & $0.37,13.9^{\mathrm{i}}$ \\
\hline Diclofenac & Analgesics & 294 & - & 704 & $4.5-4.8^{\mathrm{c}}$ & $4.1-4.2^{\mathrm{c}}$ \\
\hline Diuron & Herbicide & 233 & 0 & 436 & $3.49^{\mathrm{m}}$ & $1.7^{\mathrm{b}}, 13.8^{\mathrm{b}}$ \\
\hline Gemfibrozil & Lipid regulator & 250 & - & 556 & $4.77^{\mathrm{d}}$ & $4.7^{\mathrm{d}}$ \\
\hline Ibuprofen & Analgesic & 206 & - & 336 & $3.5-4.5^{\mathrm{c}}$ & $4.9-5.2^{\mathrm{c}}$ \\
\hline Naproxen & Analgesics & 230 & - & 1318 & $3.2^{\mathrm{c}}$ & $4.2^{\mathrm{c}} ; 4.15^{\mathrm{a}}$ \\
\hline Paracetamol & Pain reliever & 151 & 0 & 121 & $0.46^{\mathrm{k}}$ & $9.38^{\mathrm{k}}$ \\
\hline Saccharin & Artificial sweetener & 183 & - & 2540 & $0.91^{1}$ & \\
\hline Sulfamethoxazole & Antibiotic & 253 & - & 672 & $0.89^{d}$ & $2.1^{\mathrm{d}} ;<2^{\mathrm{d}}$ \\
\hline Triclocarban & Antibacterial agent & 316 & 0 & 98 & $4.9^{\mathrm{g}}$ & $12.7^{\mathrm{g}}$ \\
\hline Triclosan & Detergents & 290 & 0 & 179 & $4.76^{\mathrm{a}}$ & $7.9^{\mathrm{c}}$ \\
\hline Trimethoprim & Antibiotic & 290 & 0 & 880 & $0.91^{\mathrm{a}}$ & $6.6-7.2^{\mathrm{c}} ; 7.12^{\mathrm{a}}$ \\
\hline Verapamil & Hypertension & 454 & + & 82 & $3.79^{\mathrm{b}}$ & $8.92^{\mathrm{b}}$ \\
\hline
\end{tabular}

${ }^{a}$ U.S. National Library of Medicine (http://chem.sis.nlm.nih.gov/chemidplus/rn/52-53-9), ${ }^{a} \mathrm{MW}$ : molecular weight; ${ }^{b}$ Calculated with Advanced Chemistry Development (ACD/Labs) Software V9.04 for Solaris; ${ }^{\mathrm{c}}$ Serrano et al. (2011); ${ }^{\mathrm{d}}$ Westerhoff et al. (2005); ${ }^{\mathrm{e}}$ Yang et al. (2011); ${ }^{\mathrm{f}} \mathrm{Hapeshi}$ et al.

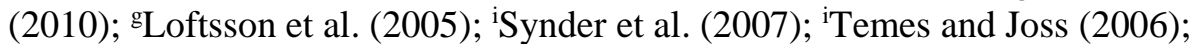
ihttps://pubchem.ncbi.nlm.nih.gov/compound/benzophenone; ${ }^{k}$ Shanmuganathan et al. (2017); lhttps://pubchem.ncbi.nlm.nih.gov/compound/saccharin; ${ }^{\text {mKimura et al. (2003) }}$ 


\subsection{Batch adsorption of DOC and total MOPs}

Batch equilibrium adsorption of DOC and MOPs in ROC on GAC showed that the percentage adsorption of these compounds increased with GAC dose and the percentage adsorption of each MOP at the highest dose of GAC was higher than that of DOC, despite MOPs concentration in ROC being 1000 times smaller than that of DOC (Fig. 1). This indicates that MOPs have higher adsorbability than DOC on GAC. However, the amount of DOC adsorbed per unit weight of GAC is much higher than that of MOPs as a result of its higher concentration in the ROC (Fig. 2). Of the MOPs, benzotriazole had the highest amount adsorbed (Fig. 2) because of its highest concentration in the ROC (Table 2). The difference in the percentage removal narrowed at the highest GAC dose due to reduced competition between DOC and MOPs for adsorption as a result of the increased number of adsorption sites at higher dose of GAC. 


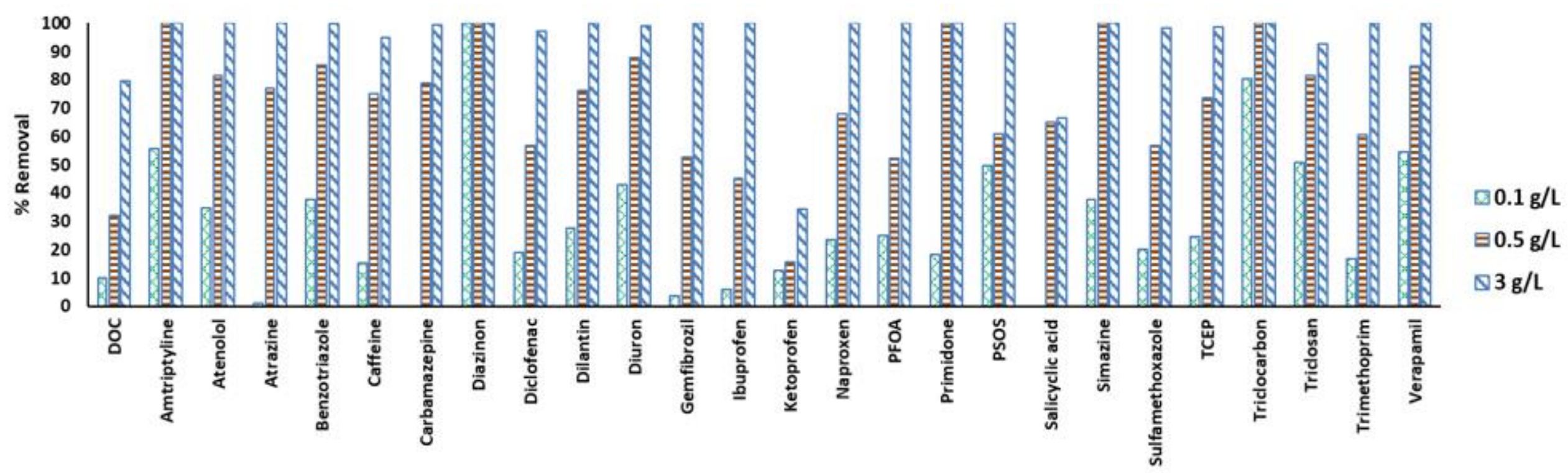

Fig. 1. Percentage removal of DOC and MOPs from ROC by adsorption onto GAC at three doses in batch experiment. 


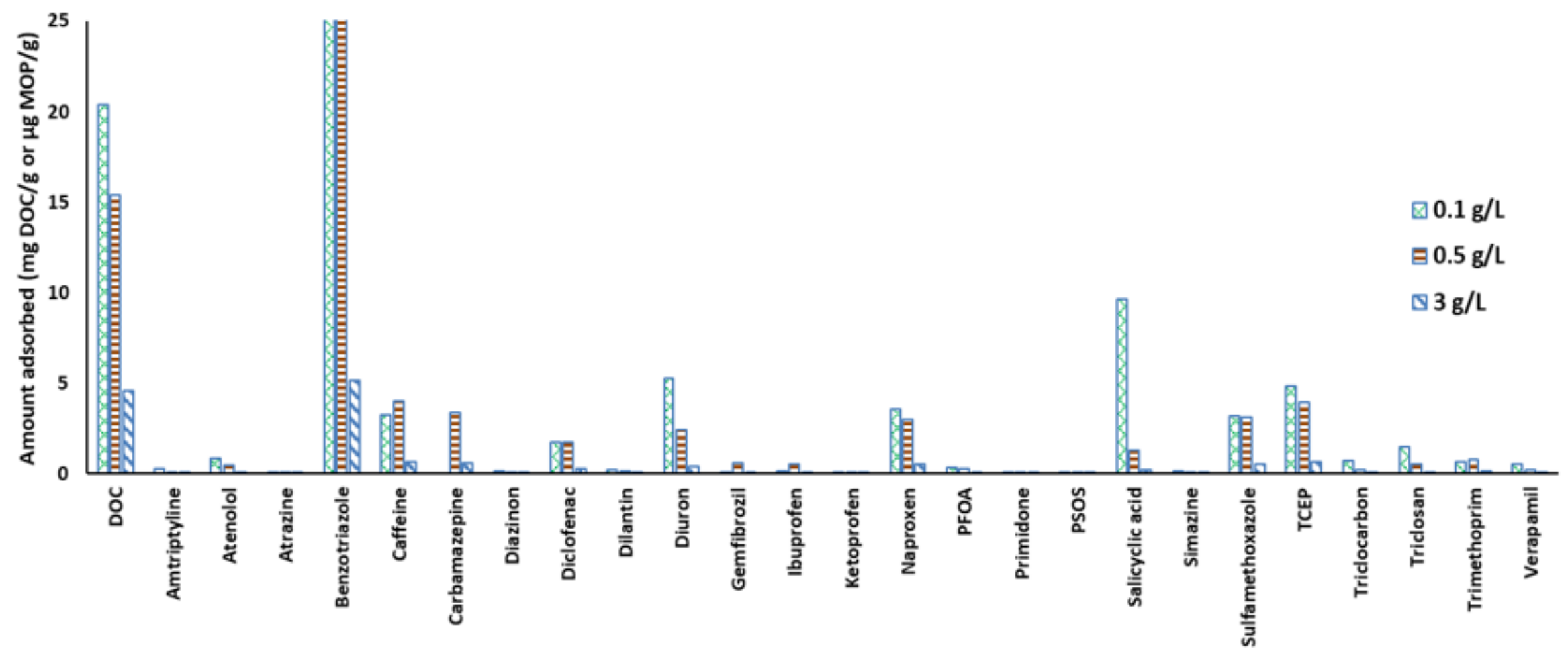

Fig. 2. Amounts of DOC and MOPs adsorbed by GAC at three doses in batch experiment. 


\subsection{Column adsorption of DOC fractions}

The breakthrough curves for DOC and its fractions in GAC column are presented in Fig. 3. Increased proportions of the influent DOC were detected in the effluent with increased bed volumes due to reduced adsorption. From bed volumes of 10 to 100 the breakthrough $(\mathrm{Ct} / \mathrm{Co})$ of DOC increased from 0.4 to 0.6 (in other words, the removal of DOC decreased from $60 \%$ to $40 \%$ ). The incomplete breakthrough suggests that the GAC column is capable of effectively remove DOC for more bed volumes. GAC removed both the hydrophobic and hydrophilic fractions, but proved to be more effective in removing the hydrophobic fraction as reported by Shanmuganathan et al. (2015). The hydrophilic fraction removal is due to anion exchange, surface complexation, and H-bonding (Nguyen et al. 2012), whereas the hydrophobics removal is due to hydrophobic interaction between the hydrophobic organic compounds and hydrophobic carbon surface of GAC (Moreno-Castilla 2004).

The removal of hydrophilic fractions increased in the order of decreasing molecular weight. Biopolymers having very high molecular weight (> 10,000 Da) were least adsorbed $(\mathrm{Ct} / \mathrm{Co}=0.6-1.0)$ and reached saturation of the GAC at 100 bed volumes. This is because of the size exclusion effect where the large molecules were unable to move into the micro and meso pores of GAC. Velten et al. (2011) also found that biopolymers had 80-90\% breakthrough at the start of the experiment and reached saturation of GAC much quicker than other DOC fractions. The degree of breakthrough of the various DOC fractions followed the order, biopolymers $>$ building blocks $>$ humic substances $>$ low molecular weight organics. The low molecular weight neutrals breakthrough was the lowest, which was consistent with its lowest molecular weight. This may have helped them to access more adsorption sites in 
the mesopores $(73-75 \%)$ and larger micropores $(<25-27 \%)$ of the GAC (Eeshwarasinghe et al. 2018).

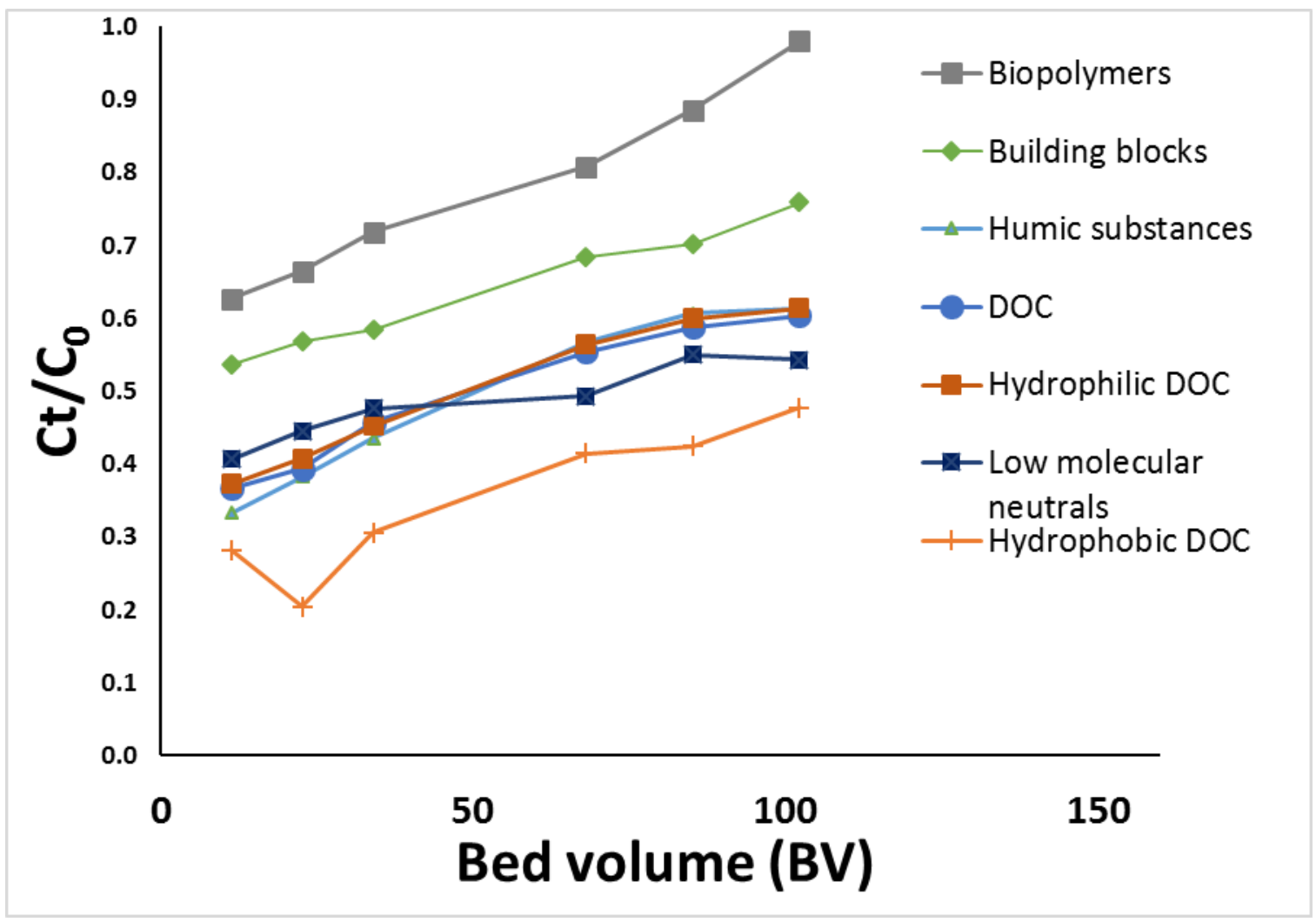

Fig. 3. GAC column breakthrough curves for DOC and its fractions in ROC.

The amounts of the DOC fractions adsorbed followed the order of the concentrations of the DOC fractions in ROC feed: hydrophilic fraction > hydrophobic fraction; humics > low molecular weight fraction > building blocks > biopolymers (Fig. 4A). These orders are the same as those reported by Shanmuganathan et al. (2015). However, Velten et al. (2011) reported the order of adsorption capacities of the DOC fractions on two GACs as humics > building blocks $>$ low molecular weight organics $>$ biopolymers. The reason for the building blocks having higher adsorption capacity than low molecular weight organics is that the concentration of the former was higher than the latter in the feed river water they used for remediation. As expected from the breakthrough curves (Fig. 3) which showed increased 
$\mathrm{Ct} / \mathrm{Co}$ with bed volume, the amounts adsorbed decreased with increased bed volume and the order of the amounts adsorbed was the reverse of the $\mathrm{Ct} / \mathrm{Co}$.

The amounts of DOC fractions adsorbed do not reflect the relative affinities of their adsorption on GAC because they are controlled by their solution concentrations. However, the amount adsorbed per unit solution concentration of the fractions which is defined by the partition coefficient (explained in section 2.6) (Nam et. al. 2014; Velten et al. 2011) is a measure of the affinity or adsorbability of the fractions on GAC. The partition coefficient, like the amount adsorbed, also decreased with increasing bed volume due to declining amounts of DOC and fractions adsorbed onto GAC with increasing bed volume (Fig. 4B). Among the DOC fractions, at bed volumes higher than 60, it decreased in the order, low molecular weight organics $(<350 \mathrm{~g} / \mathrm{mol})>$ humics $(500-1200 \mathrm{~g} / \mathrm{mol})>$ building blocks $(350$ $500 \mathrm{~g} / \mathrm{mol}$ ) $>$ biopolymers $>20,000 \mathrm{~g} / \mathrm{mol}$ ). This order is the same as the molecular weight order, except humics with higher molecular weight than building blocks had higher partition coefficient, which was contrary to the size exclusion effect exerted by the GAC pores. Other mechanisms such as H-bonding, anion exchange or hydrophobicity which may favour adsorption of humics to building blocks could have been operating in the adsorption process. 

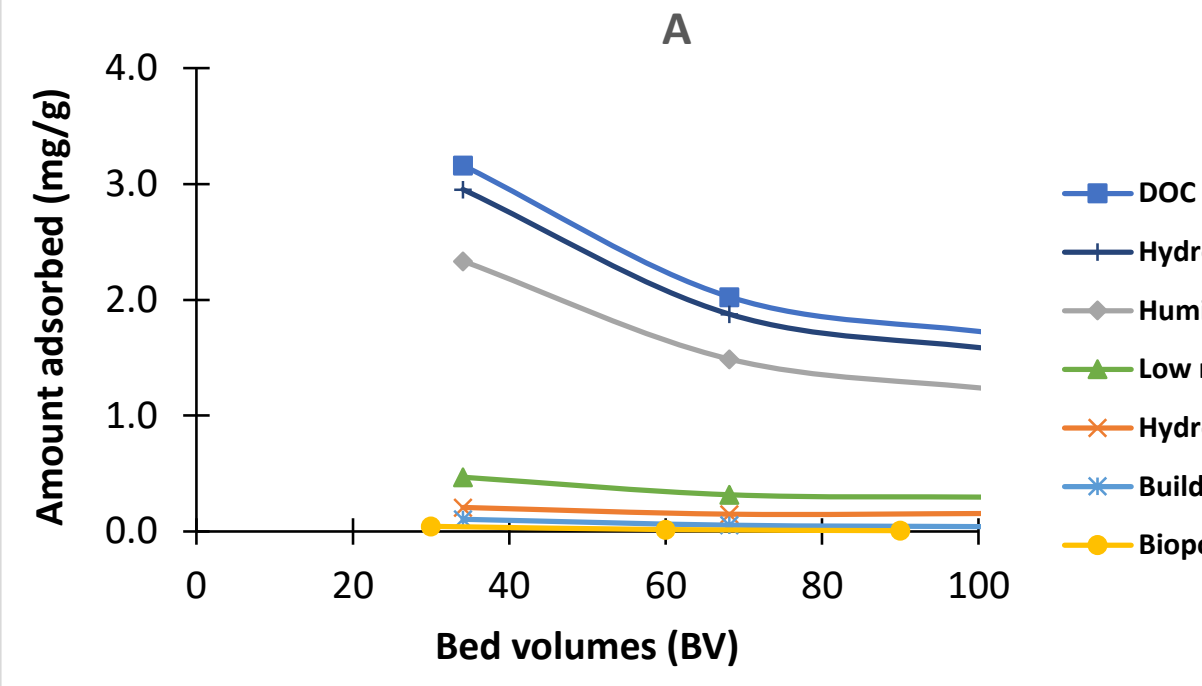

+ Hydrophilic DOC

Humics

- Low molecular neutrals

$\leftarrow$ Hydrophobic DOC

* Building blocks

- Biopolymers

Bed volumes (BV)

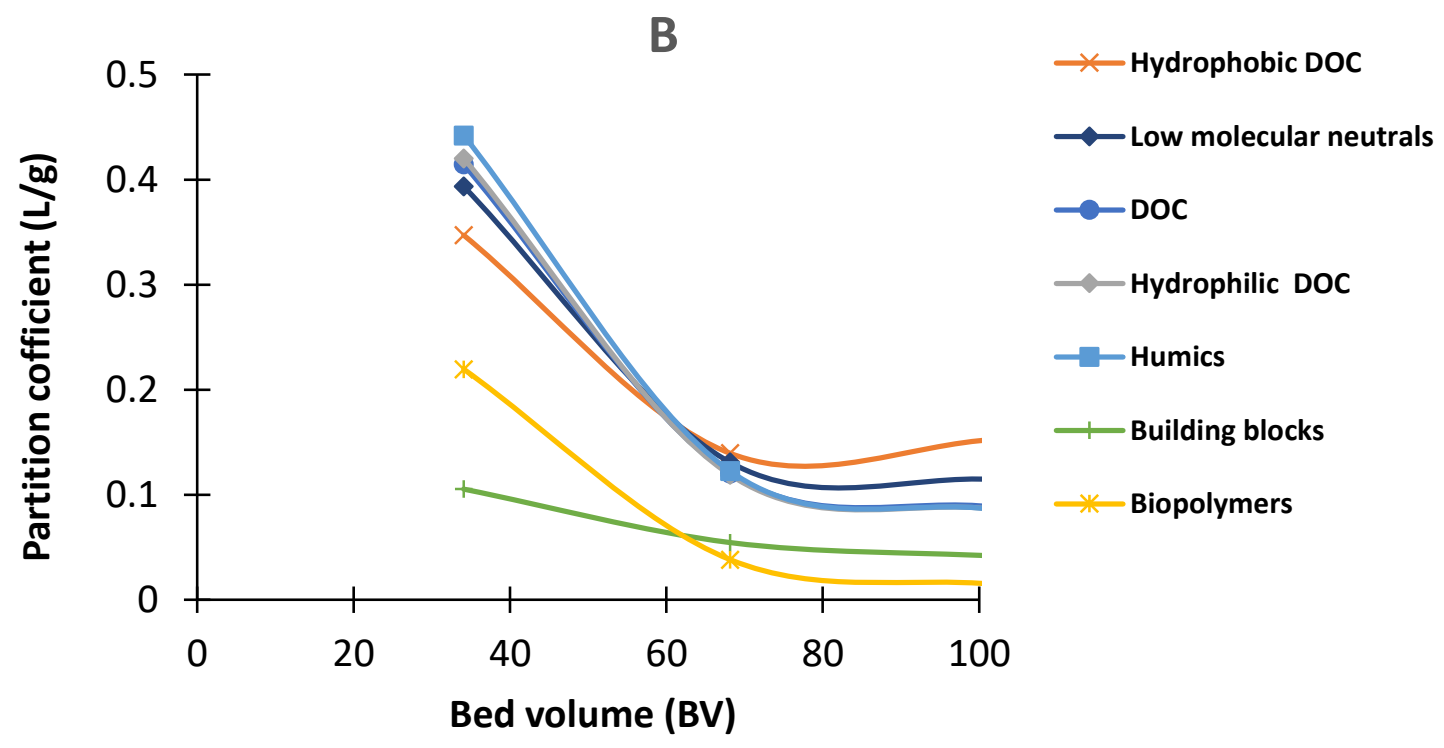

Fig. 4. Amounts of DOC fractions adsorbed and partition coefficients in GAC column. 


\subsection{Column adsorption of MOPs}

According to the literature the adsorption capacity of MOP on GAC is mainly controlled by the hydrophobicity and electrical charge of the MOP (Wang and Wang 2016). Hydrophobicity as measured by $\log$ Kow has been shown to explain the adsorption capacity of several MOPs on GAC (Nam et al. 2014; Snyder et al. 2007; Wang and Wang 2016; Westerhoff et al. 2005) - MOPs characterised by higher hydrophobicity had greater amounts adsorbed. GAC used in this study has a net negative surface charge at neutral $\mathrm{pH}$ (Eeshwarasinghe et al. 2018). Therefore, GAC preferentially adsorbs positively charged MOPs than negatively charged MOPs.

Considering the above information, the removal capacities of the 18 MOPs by GAC were divided into four groups based on the MOP charge and log Kow (Fig. 5). MOPs in Group A have favourable charge (positive or zero charge) and log Kow > 3.5 (high hydrophobicity) for adsorption onto the negatively charged hydrophobic GAC surface. MOPs in Group B also have positive or zero charge but with log Kow < 3.5 (low hydrophobicity). MOPs in Group C are negatively charged with $\log$ Kow > 3.5. The MOPs in the last group (Group D), also have negative charge but with $\log$ Kow $<3.5$. The experimental results showed that the removal efficiency of the MOPs followed the order of Group A > Group B > Groups C and D. Majority of the MOPs in Group A (3 out of 4) had 100\% removal efficiency with the exception of diuron which had a removal efficiency of $95 \%$. Majority of MOPs in Group B had an average removal efficiency of 94\% (range 90-99\%) (bisphenol A an exception with $76 \%$ removal efficiency). The MOPs that are negatively charged regardless of the hydrophobicity character (Groups C and D) had the lowest removal percentage (average $85 \%$, range $82-94 \%$ ), with diclofenac as an exception having $73 \%$ average removal. These results show that the groupings made in Fig. 5 based on charge and hydrophobicity generally explained well the adsorptive removal of MOPs by GAC. The inability to clearly demarcate 
the removal efficiencies on the basis of hydrophobicity when the MOPs have negative charges (Groups C and D) could be due to other factors operating on the MOP/GAC interaction. These include, for example, H-bonding, van der Waals forces, and $\pi$ - $\pi$ bonding (Löwenberg et al. 2014; Nguyen et al. 2013). The distribution of the MOPs into the four groups depicted in Fig. 5 may sometimes change if a GAC of different characteristics such as surface charge and functional groups is used (Noh and Schwarz 1990).

The amounts of MOPs adsorbed (Table 3, ng/g $-\mu \mathrm{g} / \mathrm{g}$ ) were much smaller compared to DOC fractions adsorbed (Fig. 4A, $\mu \mathrm{g} / \mathrm{g}-\mathrm{mg} / \mathrm{g}$ ). This is due to the large differences in their concentrations in the ROC feed (Tables 1 and 2). Similarly, the differences in the amounts adsorbed between the individual MOPs mainly depend on the individual MOP concentration in the ROC feed. However, the affinity of the MOPs towards GAC or their adsorbability, which is independent of its concentration in ROC, can be assessed using the partition coefficient as done for DOC fractions (Fig. 4B). The partition coefficients for MOPs (0.21$21.6 \mathrm{~L} / \mathrm{g}$; for MOPs which had $100 \%$ removal, solution concentration was taken to be the limit of detection of $5 \mathrm{ng} / \mathrm{L}$, Table 3$)$ were much higher than those for DOC fractions $(0.01$ $0.5 \mathrm{~L} / \mathrm{g}$, Fig. 4B). Among the MOPs, those in Group A had the highest partition coefficients while those in Groups $C$ and D had the lowest partition coefficients. Both the amount of adsorption and partition coefficient decreased over time (Table 3) due to the reduced number of vacant sites available for further adsorption.

\subsection{Practicability and economics of GAC use}

Considering the high removal capacities of DOC and MOPs by GAC obtained in the study the practicality and economics of the use of GAC in real plant operation is examined in this section. GAC is a versatile and practical adsorbent used in water treatment plants 
throughout the world because of its ability to adsorb a wide variety of organic compounds (Hung et al. 2005). However, the economics of its use depend on its market price relative to that of the treated water and the volume of water that can be treated in one adsorption cycle. Tiruneh et al. (2016) conducted a cost-benefit analysis and reported that it was economically favourable to treat grey waters using GAC in Swaziland to supply clean water to the cities. Our on-going field study with GAC column $(50 \mathrm{~cm}$ height and filtration velocity of $6.3 \mathrm{~m} / \mathrm{h}$ ) showed MOP removal to meet the required standards even after 30 days which corresponds to 1450 bed volumes.

Instead of using the GAC only once, if the spent GAC can be regenerated economically and reused, the cost-benefit would further increase. However, in view of the small capacity of water reclamation of $300 \mathrm{~m}^{3}$ of ROC production/day in the treatment plants the capital cost for the regeneration may not be viable. If regeneration is considered, one of the two common methods of regeneration, namely hydrothermal process or chemical process, can be used. Of the two process the former is more efficient (Sufnarski 1999). But it may involve high energy cost, loss of carbon, and reduction in adsorption capacity. Sufnarski (1999) reported that the adsorption capacity of GAC for phenol reduced to $67 \%$ of the original value after four adsorption-regeneration cycles. Alternative to regeneration the spent GAC can be disposed-off in approved land-fills or incorporated into building materials such as cement. 

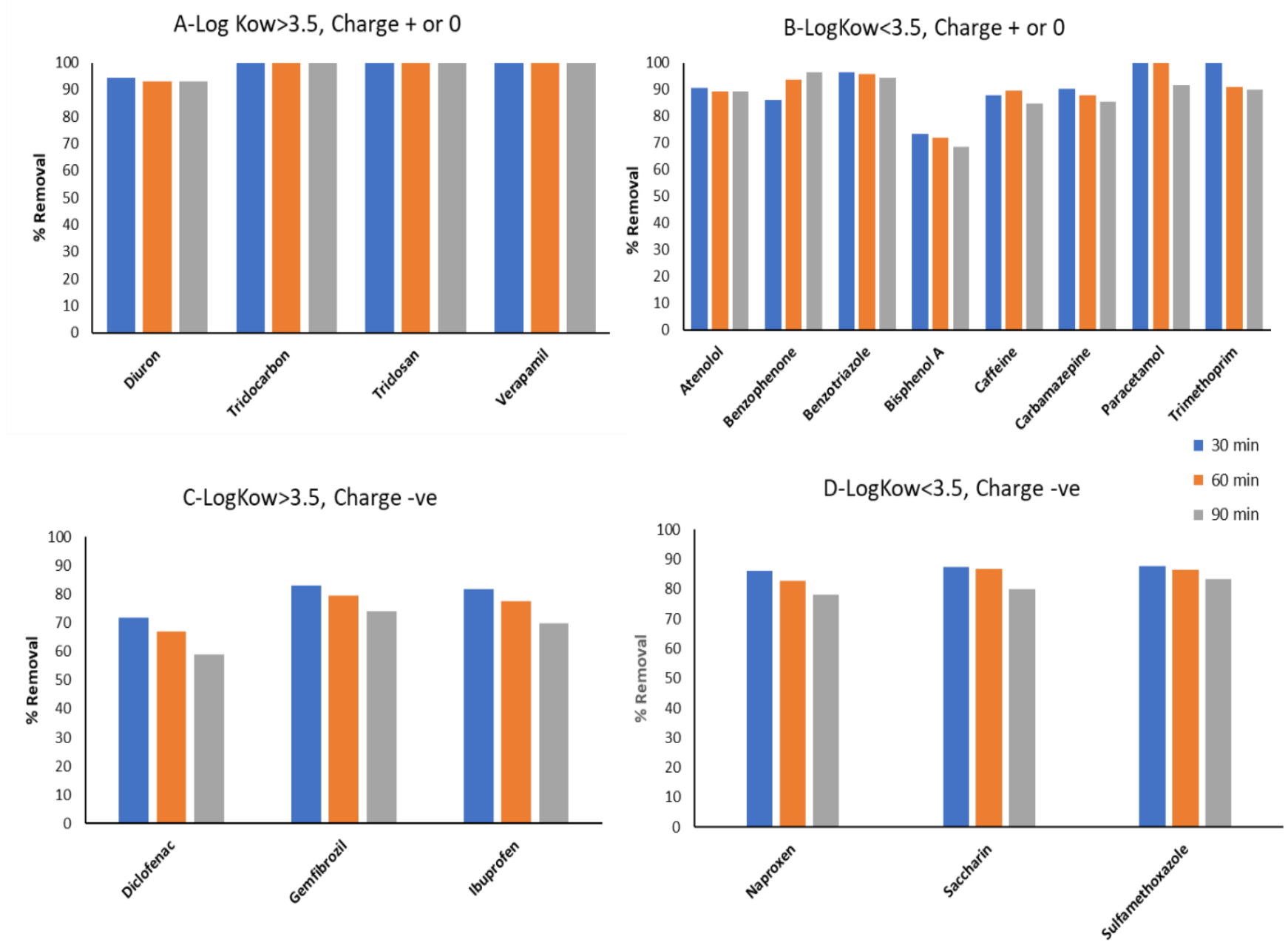

Fig. 5. Percentage removal of MOPs by GAC from ROC after 30, 60 and $90 \mathrm{~min}$ in the column experiment. 
Table 3. Amounts of MOPs adsorbed and partition coefficient* in GAC column after 30, 60 and 90 min.

\begin{tabular}{|c|c|c|c|c|c|c|c|c|c|c|c|c|}
\hline $\begin{array}{l}\text { Influent }(\mathrm{Co}) \text { and } \\
\text { effluent }(\mathrm{Ct}) \\
\text { concentration }\end{array}$ & $\begin{array}{c}\text { Total MOPs } \\
(\mathrm{ng} / \mathrm{L})\end{array}$ & $\begin{array}{c}(\% \\
\text { removal })\end{array}$ & $\begin{array}{c}\text { Amount } \\
\text { adsorbed } \\
(\mathrm{ng} / \mathrm{g})\end{array}$ & $\begin{array}{c}\text { Partition } \\
\text { coefficient, } \\
\text { Kp (L/g) }\end{array}$ & Benzotriazole & $\begin{array}{c}(\% \\
\text { removal })\end{array}$ & $\begin{array}{c}\text { Amount } \\
\text { adsorbed } \\
(\mathrm{ng} / \mathrm{g})\end{array}$ & $\begin{array}{c}\text { Partition } \\
\text { coefficient } \\
(\mathrm{L} / \mathrm{g})\end{array}$ & Diuron & $\begin{array}{l}(\% \\
\text { removal) }\end{array}$ & $\begin{array}{c}\text { Amount } \\
\text { adsorbed } \\
(\mathrm{ng} / \mathrm{g})\end{array}$ & $\begin{array}{c}\text { Partition } \\
\text { coefficient } \\
(\mathrm{L} / \mathrm{g})\end{array}$ \\
\hline $\mathrm{Co}$ & 32800 & & & & 19220 & & & & 436 & & & \\
\hline $\mathrm{Ct}, 0-30 \mathrm{~min}$ & 2428 & 96.3 & 3884 & 3.20 & 718 & 98.1 & 2319 & 6.46 & 25 & 97.1 & 52 & 4.17 \\
\hline $\mathrm{Ct}, 30-60 \mathrm{~min}$ & 2691 & 92.2 & 3718 & 1.45 & 822 & 96.0 & 2268 & 2.95 & 31 & 93.6 & 50 & 1.79 \\
\hline \multirow[t]{2}{*}{$\mathrm{Ct}, 60-90 \mathrm{~min}$} & 3361 & 90.8 & 3661 & 1.21 & 1080 & 95.1 & 2246 & 2.36 & 31 & 92.9 & 50 & 1.61 \\
\hline & Diclofenac & & & & Gemfibrozil & & & & Ibuprofen & & & \\
\hline Co & 704 & & & & 556 & & & & 336 & & & \\
\hline $\mathrm{Ct}, 0-30 \mathrm{~min}$ & 198 & 85.9 & 74 & 0.75 & 95 & 91.5 & 63 & 1.32 & 61 & 90.9 & 38 & 1.23 \\
\hline $\mathrm{Ct}, 30-60 \mathrm{~min}$ & 232 & 69.5 & 60 & 0.28 & 114 & 81.2 & 56 & 0.53 & 75 & 79.8 & 33 & 0.48 \\
\hline $\mathrm{Ct}, 60-90 \mathrm{~min}$ & 290 & 62.9 & 54 & 0.21 & 145 & 76.7 & 52 & 0.40 & 101 & 73.8 & 30 & 0.35 \\
\hline Co & 880 & & & & 1398 & & & & 1098 & & & \\
\hline $\mathrm{Ct}, 0-30 \mathrm{~min}$ & 0 & 100.0 & 108 & $21.6^{*}$ & 171 & 93.9 & 161 & 1.89 & 294 & 86.6 & 117 & 0.80 \\
\hline $\mathrm{Ct}, 30-60 \mathrm{~min}$ & 79 & 95.5 & 103 & 2.62 & 145 & 88.7 & 152 & 0.96 & 310 & 72.5 & 98 & 0.32 \\
\hline \multirow[t]{2}{*}{$\mathrm{Ct}, 60-90 \mathrm{~min}$} & 88 & 90.5 & 98 & 1.17 & 216 & 87.1 & 150 & 0.83 & 348 & 70.0 & 95 & 0.29 \\
\hline & Carbamazepine & & & & Sulfamethoxazole & & & & Naproxen & & & \\
\hline Co & 1286 & & & & 672 & & & & 1318 & & & \\
\hline $\mathrm{Ct}, 0-30 \mathrm{~min}$ & 126 & 95.1 & 150 & 2.39 & 82 & 93.9 & 78 & 1.89 & 183 & 93.1 & 151 & 1.65 \\
\hline $\mathrm{Ct}, 30-60 \mathrm{~min}$ & 156 & 89.0 & 141 & 1.00 & 92 & 87.1 & 72 & 0.83 & 226 & 84.5 & 137 & 0.67 \\
\hline $\mathrm{Ct}, 60-90 \mathrm{~min}$ & 190 & 86.5 & 137 & 0.79 & 111 & 84.9 & 70 & 0.69 & 288 & 80.5 & 130 & 0.51 \\
\hline
\end{tabular}


Table 3. (Continued)

\begin{tabular}{|c|c|c|c|c|c|c|c|c|c|c|c|c|}
\hline $\begin{array}{l}\text { Influent }(\mathrm{Co}) \text { and } \\
\text { effluent }(\mathrm{Ct}) \\
\text { concentration }\end{array}$ & & $\begin{array}{l}(\% \\
\text { removal })\end{array}$ & $\begin{array}{l}\text { Amount } \\
\text { adsorbed } \\
\text { (ng/g) }\end{array}$ & $\begin{array}{l}\text { Partition } \\
\text { coefficient, } \\
\mathrm{Kp}(\mathrm{L} / \mathrm{g})\end{array}$ & & $\begin{array}{l}(\% \\
\text { removal })\end{array}$ & $\begin{array}{l}\text { Amount } \\
\text { adsorbed } \\
(\mathrm{ng} / \mathrm{g})\end{array}$ & $\begin{array}{l}\text { Partition } \\
\text { coefficient } \\
(\mathrm{L} / \mathrm{g})\end{array}$ & & $\begin{array}{l}(\% \\
\text { removal })\end{array}$ & $\begin{array}{l}\text { Amount } \\
\text { adsorbed } \\
(\mathrm{ng} / \mathrm{g})\end{array}$ & $\begin{array}{l}\text { Partition } \\
\text { coefficient } \\
(\mathrm{L} / \mathrm{g})\end{array}$ \\
\hline & Benzophenone & & & & Paracetamol & & & & Saccharin & & & \\
\hline $\mathrm{Co}$ & 806 & & & & 121 & & & & 2540 & & & \\
\hline $\mathrm{Ct}, 0-30 \mathrm{~min}$ & 111 & 93.1 & 92 & 1.66 & 0 & 100.0 & 15 & $3.00 *$ & 322 & 93.7 & 293 & 1.82 \\
\hline $\mathrm{Ct}, 30-60 \mathrm{~min}$ & 51 & 90.0 & 89 & 1.10 & 0 & 100.0 & 15 & $3.00 *$ & 340 & 87.0 & 272 & 0.82 \\
\hline \multirow[t]{2}{*}{$\mathrm{Ct}, 60-90 \mathrm{~min}$} & 28 & 95.1 & 94 & 2.39 & 10 & 95.9 & 14 & 2.85 & 506 & 83.3 & 260 & 0.62 \\
\hline & Atenolol & & & & Triclocarbon & & & & Veeraprail & & & \\
\hline Co & 128 & & & & 98 & & & & 82 & & & \\
\hline $\mathrm{Ct}, 0-30 \mathrm{~min}$ & 12 & 95.3 & 15 & 2.50 & 0 & 100.0 & 12 & $2.4^{*}$ & 0 & 100.0 & 10 & $2.00 *$ \\
\hline $\mathrm{Ct}, 30-60 \mathrm{~min}$ & 14 & 89.8 & 14 & 1.09 & 0 & 100.0 & 12 & $2.4^{*}$ & 0 & 100.0 & 10 & $2.00 *$ \\
\hline $\mathrm{Ct}, 60-90 \mathrm{~min}$ & Triclosan & & & & & & & & & & & \\
\hline $\mathrm{Co}$ & 179 & & & & & & & & & & & \\
\hline $\mathrm{Ct}, 0-30 \mathrm{~min}$ & 0 & 100.0 & 22 & $4.40 *$ & & & & & & & & \\
\hline $\mathrm{Ct}, 30-60 \mathrm{~min}$ & 0 & 100.0 & 22 & $4.40 *$ & & & & & & & & \\
\hline $\mathrm{Ct}, 60-90 \mathrm{~min}$ & 0 & 100.0 & 22 & $4.40 *$ & & & & & & & & \\
\hline
\end{tabular}

*partition coefficient calculated assuming solution concentration is the instrument's detection limit $(5 \mathrm{ng} / \mathrm{L})$ instead of zero solution concentration that was measured 


\section{Conclusions}

Both batch and column experiments confirmed that GAC is an efficient adsorbent for simultaneous removal of DOC and MOPs when they are present together in ROC, thus reducing the environmental hazard if ROC is disposed of on lands or in natural water bodies. The amounts of DOC fractions adsorbed were several times higher than those of MOPs due mainly to the much higher concentrations of DOC fractions than the MOPs in ROC. Of the different DOC fractions the hydrophilic fraction had higher amounts adsorbed than the hydrophobic fraction, while biopolymers had the lowest amounts adsorbed among the hydrophilic fractions. This is very much related to their concentrations in ROC. The partition coefficient which is a measure of the adsorbability or affinity of the DOC fractions towards GAC and independent of the concentrations in ROC followed the order, low molecular weight organics $>$ humics $>$ building blocks $>$ biopolymers. It was much higher for the MOPs than for DOC fractions.

The 18 MOPs studied were classified into four groups based on hydrophobicity (log Kow) and electric charge; Group A (4 MOPs with positive or neutral charge and log Kow > 3.5), Group B (8 MOPs with positive or neutral charge and $\log$ Kow < 3.5), Group C (3 MOPs with negative charge and log Kow > 3.5), Group D (3 MOPs with negative charge and $\log$ Kow < 3.5). The experimental results showed that the removal efficiency of the MOPs followed the order of Group A > Group B > Groups C and D.

The results of this study can provide important background information for designing an effective water treatment process for simultaneously removing DOC and MOPs in real full-scale plants. We recommend that the results be tested in long-term pilot plant experiments by also examining other GACs and other adsorbents for example Purolite ion exchange resins having different surface chemical properties such as charges and functional groups. 


\section{Acknowledgement}

We are grateful to the Cooperative Research Centre for Contamination Assessment and Remediation of the Environment (CRC CARE) (project number 4.1.10-14/15) for providing financial support for this study. We thank Drs James McDonald and Stuart Khan of University of New South Wales, Australia for help in analysing MOPs.

\section{Author Contributions}

Conceived and designed the experiments: Jaya Kandasamy, Paripurnanda Loganathan and Saravanamuthu Vigneswaran. Experiments and chemical analysis conducted: Shahzad Jamil and Chinu Khourshed. Analysis and interpretation of the data: Shahzad Jamil and Paripurnanda Loganathan. All authors contributed to the preparation of the paper. All authors read and approved the manuscript

\section{References}

Amy, G.L., Rodriguez, S.G.S., Kennedy, M.D., Schippers, J.C., Remize, P.J., Barbe, C., Manes, C.L.de O., West, N.J., Lebaron, P., van der Kooij, D., Veenendaal, H., Schaule, G., Petrowski, K., Huber, S., Sim, L.N., Ye, Y., Chen, V., Fane, A.G., 2011. Chapter 1. Water Quality Assessment Tools, Membrane Based Desalination, An Integrated Approach (MEDINA), IWA Publishing Alliance House, London SWIH OQS, UK.

Cheng, W., Dastgheib, S.A., Karanfil, T., 2005. Adsorption of dissolved natural organic matter (DOM) by virgin and modified granular activated carbons. Water Res. 39, 2281-2290.

de Ridder, D.J., McConville, M., Verliefde, A.R.D., van der Aa, L.T.J., Heijman, S.G.J., 
Verberk, J.Q.J.C., Rietveld, L.C., van Dijk, J.C., 2009. Development of a predictive model to determine micropollutant removal using granular activated carbon. Drinking Water Engineer. Sci. 2, 57-62.

Eeshwarasinghe, D., Loganathan, P., Kalaruban, M., Sounthararajah, D.P., Kandasamy, J., Vigneswaran, S., 2018. Removing polycyclic aromatic hydrocarbons from water using granular activated carbon: kinetic and equilibrium adsorption studies. Environ. Sci. Pollut. Res. 25, 13511-13524.

Fick, J., Lindberg, R.H., Tysklind, M., Larsson, D.G.J., 2010. Predicted critical environmental concentrations for 500 pharmaceuticals. Regul. Toxicol. Pharmacol. $58,516-523$.

Hapeshi, E., Achilleos, A., Vasquez, M.I., Michael, C., Xekoukoulotakis, N.P., Mantzavinos, D., Kassinos, D., 2010. Drugs degrading photocatalytically: kinetics and mechanisms of ofloxacin and atenolol removal on titania suspensions. Water Res. 44, 1737-1746.

Huber, S.A., Balz, A., Abert, M., Pronk, W., 2011. Characterisation of aquatic humic and non-humic matter with size exclusion chromatography-organic carbon detection organic nitrogen detection (LC-OCD-OND). Water Res. 45, 879-885.

Hung, Y., Lo, H.H., Wang, L.K., Taricska, J.R., Li, K.H., 2005. Granular activated carbon adsorption. In: Physicochemical Treatment Processes (Editors; Wang, L.K., Hung, Y., Shammas, N.K.), Vol. 3, 573-633. Humana Press, Totowa, New Jersey.

Jamil, S., Jeong, S., Vigneswaran, S., 2016. Application of pressure assisted forward osmosis for water purification and reuse of reverse osmosis concentrate from a water reclamation plant. Sep. Purif. Tech. 171, 182-190. 
Jamil, S., Jeong, S., Vigneswaran, S., 2018. Application of forward osmosis membrane in nanofiltration mode to treat reverse osmosis concentrate from wastewater reclamation plants. Water Sci. Technol. 77, 1990-1997.

Kimura, K., Amy, G., Drewes, J.E., Heberer, T., Kim, T., Watanabe, Y., 2003. Rejection of micropollutants (disinfection by-products, endocrine disrupting compounds, and pharmaceutically active compounds) by NF/RO membranes. J. Mem. Sci. 227, 113121.

Loftsson, T., Hreinsdóttir, D., Másson, M., 2005. Evaluation of cyclodextrin solubilization of drugs. Int. J. Pharm. 302, 18-28.

Löwenberg, J., Zenker, A., Baggenstos, M., Koch, G., Kazner, C., Wintgens, T., 2014. Comparison of two PAC/UF processes for the removal of micropollutants from wastewater treatment plant effluents: process performance and removal efficiency. Water Res. 56, 26-36.

Moreno-Castilla, C., 2004. Adsorption of organic molecules from aqueous solutions on carbon materials. Carbon, 42, 83-94.

Nam, S., Choi, D., Kim, S., Her, N., Zoh, K., 2014. Adsorption characteristics of selected hydrophilic and hydrophobic micropollutants in water using activated carbon. J. Hazard. Mater. 270, 144-152.

Nguyen, L.N., Hai, F.I., Kang, J., Price, W.E., Nghiem, L.D., 2012. Removal of trace organic contaminants by a membrane bioreactor-granular activated carbon (MBR-GAC) system. Bioresource Technol. 113, 169-173.

Nguyen, L.N., Hai, F.I., Kang, J., Price, W.E., Nghiem, L.D., 2013. Coupling granular activated carbon adsorption with membrane bioreactor treatment for trace organic 
contaminant removal: breakthrough behaviour of persistent and hydrophilic compounds. J. Environ. Manage. 119, 173-181.

Noh, J.S., Schwarz, J.A., 1990. Effect of $\mathrm{HNO}_{3}$ treatment on the surface acidity of activated carbons. Carbon 28, 675-682.

Pal, A., Gin, K.Y.H., Lin, A.Y.C., Reinhard, M., 2010. Impacts of emerging organic contaminants on freshwater resources: review of recent occurrences, sources, fate and effects. Sci. Total Environ. 408, 6062-6069.

Serrano, D., Suárez, S., Lema, J.M., Omil, F., 2011. Removal of persistent pharmaceutical micropollutants from sewage by addition of PAC in a sequential membrane bioreactor, Water Res. 45, 5323-5333.

Shanmuganathan, S., Loganathan, P., Kazner, C., Johir, M.A.H., Vigneswaran, S., 2017. Submerged membrane filtration adsorption hybrid system for the removal of organic micropollutants from a water reclamation plant reverse osmosis concentrate. Desalination, 401, 134-141.

Shanmuganathan, S., Nguyen, T.V., Jeong, S., Kandasamy, J., Vigneswaran, S., 2015. Submerged membrane - (GAC) adsorption hybrid system in reverse osmosis concentrate treatment. Sep. Purif. Technol. 146, 8-14.

Shanmuganathan, S., Nguyen, T.V., Shim, W.G., Kandasamy, J., Vigneswaran, S., 2014. Performance of submerged membrane - ion exchange hybrid system with Purolite A502PS in treating reverse osmosis feed. Sep. Purif. Technol. 122, 24-31.

Snyder, S.A., Adham, S., Redding, A.M., Cannon, F.S., De Carolis, J., Oppenheimer, J., Wert, E.C., Yoon, Y., 2007. Role of membranes and activated carbon in the removal of endocrine disruptors and pharmaceuticals. Desalination, 202, 156-181. 
Sounthararajah, D.P., Loganathan, P., Kandasamy, J., Vigneswaran, S., 2016. Column studies on the removal of dissolved organic carbon, turbidity and heavy metals from stormwater using granular activated carbon. Desalination Water Treat. 57, 5045-5055.

Sufnarski, M.D., 1999. The Regeneration of Granular Activated Carbon Using Hydrothermal Technology. M.Sc. Engineering thesis submitted to The University of Texas at Austin. May 1999, 92 pages.

Ternes, T.A., Joss, A. (Eds.), 2006. Human Pharmaceuticals, Hormones and Fragrances - The Challenge of Micropollutants in Urban Water Management. IWA Publishing, London. Tiruneh, A.T., Fadiran, A.O., Ndlela, W.N., Heikkilaä, J., 2016. Assessment of technical and economic feasibility of activated charcoal removal of organic matter from different streams of grey water through study of adsorption isotherms. Am. J. Environ. Protect. $5,56-64$.

Velten, S., Knappe, D.R.U., Traber, J., Kaiser, H., von Gunten, U., Boller, M., Meylan, S., 2011. Characterisation of natural organic matter adsorption in granular activated carbon adsorbers. Water Res. 45, 3951-3959.

Wang, J., Wang, S., 2016. Removal of pharmaceuticals and personal care products (PPCPs) from wastewater: A review. J. Environ. Manage. 182, 620-640.

Westerhoff, P., Yoon, Y., Snyder, S., Wert, E., 2005. Fate of endocrine-disruptor, pharmaceutical, and personal care product chemicals during simulated drinking water treatment processes. Environ. Sci. Technol. 39, 6649-6663.

Yang, X., Flowers, R.C., Weinberg, H.S., Singer, P.C., 2011. Occurrence and removal of pharmaceuticals and personal care products (PPCPs) in an advanced wastewater reclamation plant. Water Res. 45, 5218-5228. 